\title{
Detecting Long-Term Deformation of a Loess Landslide from the Phase and Amplitude of Satellite SAR Images: A Retrospective Analysis for the Closure of a Tunnel Event
}

\author{
Yaru Zhu ${ }^{1}$, Haijun Qiu ${ }^{1,2, *} \mathbb{C}$, Zijing Liu ${ }^{1}$, Jiading Wang ${ }^{3}$, Dongdong Yang ${ }^{1}$, Yanqian Pei ${ }^{1}$, Shuyue Ma ${ }^{1}$, \\ Chi Du ${ }^{1}$, Hesheng Sun ${ }^{1}$ and Luyao Wang ${ }^{1}$
}

1 Shaanxi Key Laboratory of Earth Surface and Environmental Carrying Capacity, College of Urban and Environmental Sciences, Northwest University, Xi'an 710127, China; zhuyaru@stumail.nwu.edu.cn (Y.Z.); liuzijing@stumail.nwu.edu.cn (Z.L.); yangdongdong@stumail.nwu.edu.cn (D.Y.); 201620795@stumail.nwu.edu.cn (Y.P.); msynwu@stumail.nwu.edu.cn (S.M.); 201920802@stumail.nwu.edu.cn (C.D.); 201920799@stumail.nwu.edu.cn (H.S.); luyaowang@stumail.nwu.edu.cn (L.W.)

2 Institute of Earth Surface System and Hazards, College of Urban and Environmental Sciences, Northwest University, Xi'an 710127, China

3 State Key Laboratory of Continental Dynamics, Department of Geology, Northwest University, Xi'an 710069, China; wangjd@nwu.edu.cn

* Correspondence: haijunqiu@nwu.edu.cn; Tel.: +86-139-9134-5616

check for updates

Citation: Zhu, Y.; Qiu, H.; Liu, Z.; Wang, J.; Yang, D.; Pei, Y.; Ma, S.; Du, C.; Sun, H.; Wang, L. Detecting Long-Term Deformation of a Loess Landslide from the Phase and Amplitude of Satellite SAR Images: A Retrospective Analysis for the Closure of a Tunnel Event. Remote Sens. 2021, 13, 4841. https:// doi.org/10.3390/rs13234841

Academic Editor: Nicola Casagli

Received: 18 October 2021

Accepted: 26 November 2021

Published: 29 November 2021

Publisher's Note: MDPI stays neutral with regard to jurisdictional claims in published maps and institutional affiliations.

Copyright: (c) 2021 by the authors. Licensee MDPI, Basel, Switzerland. This article is an open access article distributed under the terms and conditions of the Creative Commons Attribution (CC BY) license (https:/ / creativecommons.org/licenses/by/ $4.0 /)$.

\begin{abstract}
Information about the long-term spatiotemporal evolution of landslides can improve the understanding of landslides. However, since landslide deformation characteristics differ it is difficult to monitor the entire movement of a landslide using a single method. The Interferometric Synthetic Aperture Radar (InSAR) and pixel offset tracking (POT) method can complement each other when monitoring deformation at different landslide stages. Therefore, the InSAR and improved POT method were adapted to study the pre- and post-failure surface deformation characteristics of the Gaojiawan landslide to deepen understanding of the long-term spatiotemporal evolution characteristics of landslides. The results show that the deformation displacement gradient of the Gaojiawan landslide exhibited rapid movement that exceeded the measurable limit of InSAR during the first disaster. Moreover, the Gaojiawan landslide has experienced long-term creep, and while studying the post-second landslide's failure stability, the acceleration trend was identified via time series analysis, which can be used as a precursor signal for landslide disaster warning. Our study aims to provide scientific reference for local governments to help prevent and mitigate geological disasters in this region.
\end{abstract}

Keywords: landslides; pre- and post-failure deformation; time-series InSAR; improved pixel offset tracking

\section{Introduction}

Landslides and related disasters, as complex natural phenomena, cause significant casualties and serious consequences worldwide [1-5]. Landslides are distributed throughout the mountainous areas of western China [6,7]. In the transition zone between the Qinghai-Tibet Plateau and the Loess Plateau in particular, tectonics are active, the regional stability is fragile, and geological disasters are frequent [8]. Therefore, early identification and long-term monitoring of landslides are urgent tasks to provide scientific reference for landslide prediction, early warning, and preventative measures [9].

Surface deformation measurement is essential to understanding the evolution of landslides and the early warning of catastrophic damage [10-14]. However, due to the unpredictability, imperceptibility, and inaccessibility of many landslides, it is often impossible to obtain such information through traditional measurements (e.g., inclinometers, Global 
Positioning Systems (GPS), extensometers, total stations, and so on) [15]. The interferometric synthetic aperture radar (InSAR) technique can obtain subtle deformation information with high precision as well as long-time series of slow surface deformation on a large scale to reveal the evolution of landslides [16-18]. The methods of surface deformation retrieval using SAR images can be divided into phase-based and amplitude-based methods. Among these, phase-based differential SAR interferometry (DInSAR) and time-series methods have been successfully applied in a variety of studies, including early identification and inventory of landslides [19-24], surface deformation monitoring [25-29], and postdisaster analysis [30-32]. It can be used to measure subtle deformation with centimeter to millimeter-scale accuracy, but due to wavelength limitation, excessive deformation gradients will cause incoherence and wrong unwrapping results, so it is only suitable for monitoring extremely slow to very slow landslides [16,33]. In addition, amplitude-based pixel offset tracking (POT) is widely used to monitor active landslides with annual displacements of greater than tens of centimeters [34-36]. However, its accuracy is lower than that of phase-based InSAR methods, and it is often used for monitoring landslides with high deformation rates [37-39]. Analyzing the long-term spatiotemporal deformation characteristics of landslides helps improve landslide understanding and mitigate landslide disasters. However, using a single method could be insufficient for retrieving the deformation of a landslide since the entire movement process of a landslide may vary considerably $[39,40]$. Li et al. [15] analyzed the pre- and post-failure evolution characteristics of the Huangnibazi landslide based on multi-temporal images. The slow movement of the slope before the failure event was detected by interference technology. Using the adaptive amplitude offset tracking method, the large displacement after the landslide failure was successfully retrieved with meter-level accuracy. Xiong et al. [40] retrieved the pre- and post-failure spatiotemporal deformation history of the Baige landslide based on multi-satellite images and hybrid remote sensing technology, and obtained the surface displacement before the first failure event using cross-correlation technology and pixel offset tracking technology. Based on the Multi-temporal Synthetic Aperture Radar Interferometry (MT-InSAR) method, the displacement velocity map after the second failure was obtained. As a result, these two methods can complement each other in landslide deformation measurement during different stages, and can provide reliable identification and monitoring for landslide research and analysis.

In this study, therefore, we combined these two methods to comprehensively study and analyze the Gaojiawan landslide in the transition zone between the Qinghai-Tibet Plateau and the Loess Plateau. First, the small baseline subset (SBAS) time series method was applied to Sentinel-1A datasets to retrieve the pre-first failure movements on the slope, while an improved POT method was used to retrieve the large-scale displacements during the disaster. In addition, the pre-second and post-second failure deformation velocity and cumulative displacement of the Gaojiawan landslide were explored using the SBAS time series method to understand its long-term spatiotemporal evolution.

\section{Study Area}

The study area is located in the southeastern part of the Ledu District, Qinghai Province (Figure 1a,b). Several important highways connecting eastern and western China, including the G109 national Highway and the Zhangjiazhuang tunnel, cross this area (Figure 1c). The construction of the Zhangjiazhuang tunnel in this region started in 2010 and was completed in early 2012 [8]. But the Zhangjiazhuang tunnel was closed twice, on 18 January 2016 and 25 December 2018, respectively [41]. The study area lies in a transition zone between the Qinghai-Tibet Plateau and the Loess Plateau, where there are active tectonic and frequent earthquake events [8,42]. Two subparallel strike-slip faults located on both sides of the entrance and exit of the Zhangiiazhuang tunnel (Figure 2) control the formation of the hills and valleys in the study area [8]. This region has a typical plateau continental climate, and the average annual temperature and precipitation are approximately $7.3{ }^{\circ} \mathrm{C}$ and $335.4 \mathrm{~mm}$, respectively [43]. 


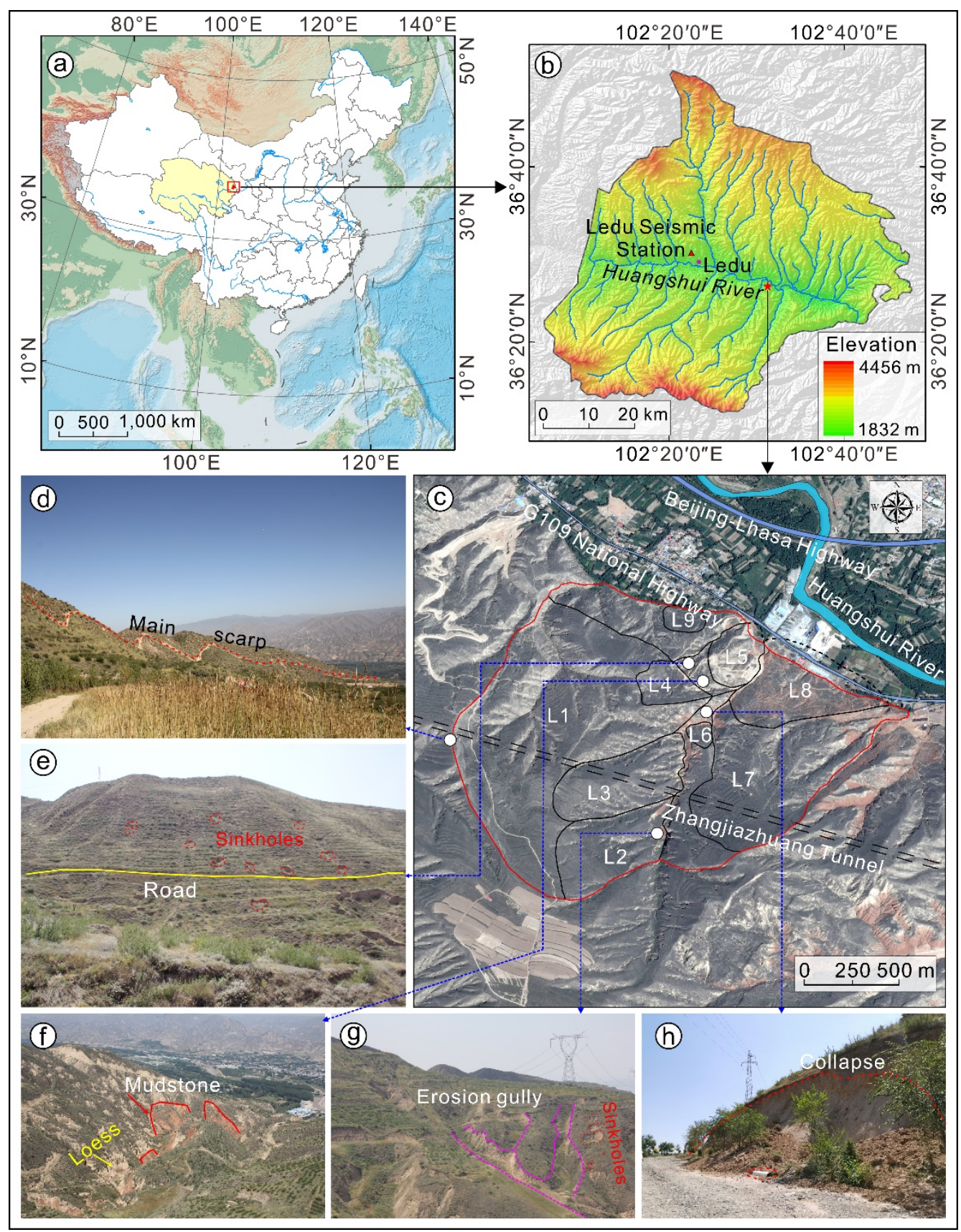

Figure 1. Study area and field investigation. (a) The yellow area shows the location of the Qinghai Province in China, and the red region is the Ledu District; (b) The red star marks the study area; (c) Optical image of the study area acquired on 31 December 2015, with the landslide boundary modified by Meng et al. [44]; (d) Main scarp of the landslide L1; (e) Sinkholes; (f) The outcropping lithologies; (g) Erosion gully; (h) Collapse.

The lithology of the Gaojiawan landslide is Quaternary loess and Paleogene mudstone (Figure 1f). The Gaojiawan landslide is tongue-shaped, its length, width, and maximum elevation differences approximately $483 \mathrm{~m}, 560 \mathrm{~m}$, and $563 \mathrm{~m}$, respectively. Meng [44] determined the spatial distribution of nine landslides in the Gaojiawan landslide group based on field investigations and the interpretation of aerial photographs (Figure 1c). Landslides have different slip surface shapes and volumes, which overlap each other. The largest landslide (L1) in the Gaojiawan landslide group is located in the western section of the Zhangjiazhuang tunnel (Figure 1c), and its main scarp is clearly visible and was continuously distributed for hundreds of meters (Figure 1d). After the formation 
of landslide L1, two further landslides, L2 and L3, developed to the east of landslide L1. Among them, several gullies were formed at the toe of landslide L2 (Figure 1g). There are two secondary landslides, L4 and L5, in front of landslide L1. Numerous sinkholes were also observed in landslide L4 (Figure 1e), which may provide the dominant infiltration channels for rainfall penetration [44]. The other two large-scale landslides, L7 and L8, are situated on the eastern side of the study area. Through field investigations, it was discovered that due to the reactivation of landslides in recent years, large amounts of surface deformation and damage occurred in landslide L7 (Figure 1h). It should be noted that Gaojiawan Village is located at the front of landslide L9. Moreover, based on the long short-term memory network (LSTM) model, Wang [45] extrapolated and predicted that the deformation of the Gaojiawan landslide would continue to increase without any sign of convergence. Reactivation of the landslide poses a threat to the lives, property, and well-being of the residents of Gaojiawan Village, as well as those living in adjacent areas [44].

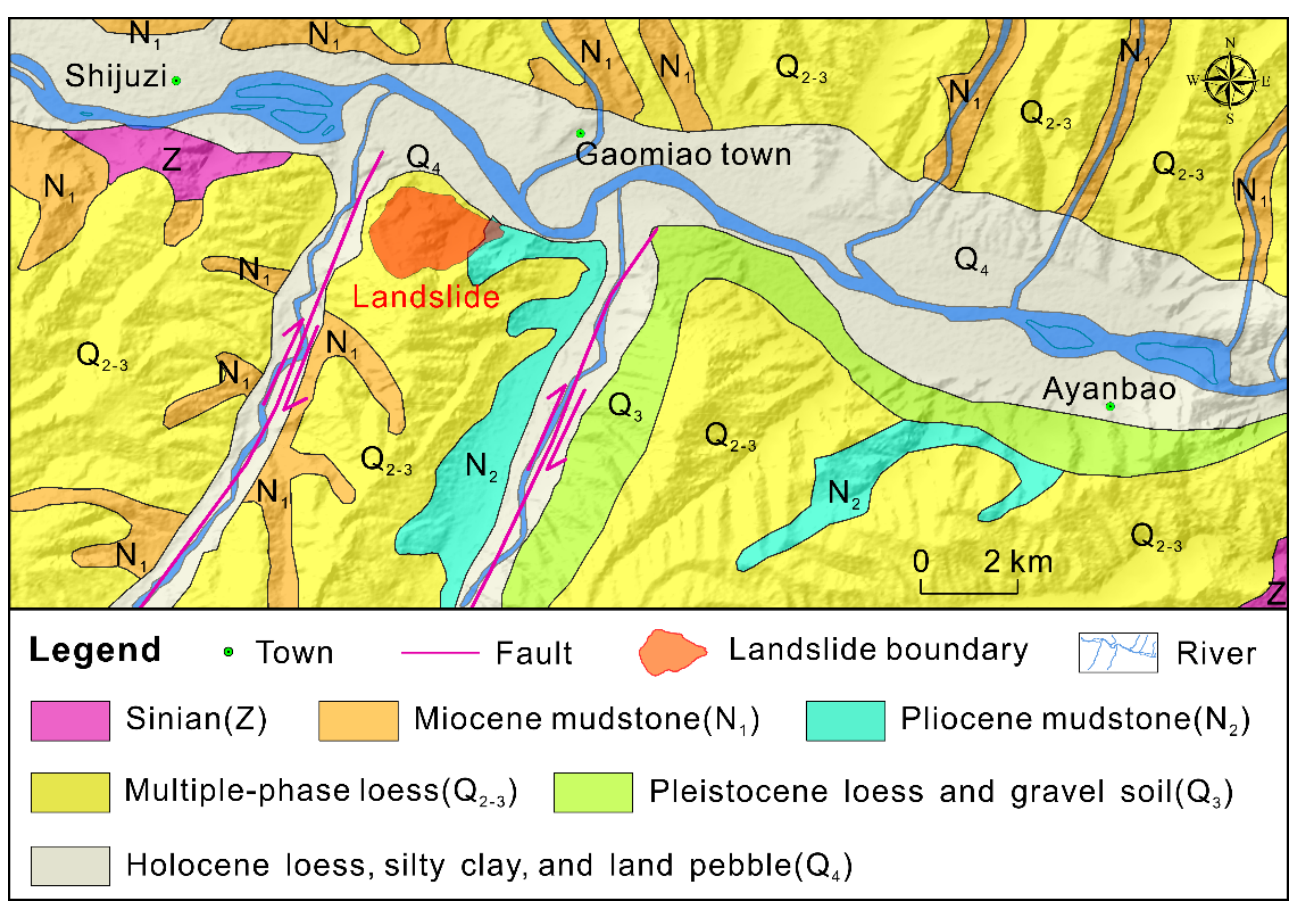

Figure 2. Geologic map of the Gaojiawan landslide (modified from Zhou et al. [8]).

\section{Materials and Methods}

\subsection{Time-Series InSAR and DInSAR Analyses}

Due to the geometrical relationship involving the side-looking imaging of SAR images, geometric distortions occur, including shadowing, layover, and foreshortening, which is likely to cause blind areas in single-orbit observations and seriously decrease the capability of landslide identification. A combination of ascending and descending observations could largely reduce the number of blind areas [22]. Therefore, we used multi-temporal Sentinel-1A data combined with ascending and descending datasets to study the Gaojiawan landslide. The Gaojiawan landslide experienced two failure events on 18 January 2016 and 25 December 2018. To ensure data coherence, this paper used the time of the first and second landslide failures as the node to study the surface deformation characteristics of the Gaojiawan landslide. Their temporal coverage is shown in Figure 3. 


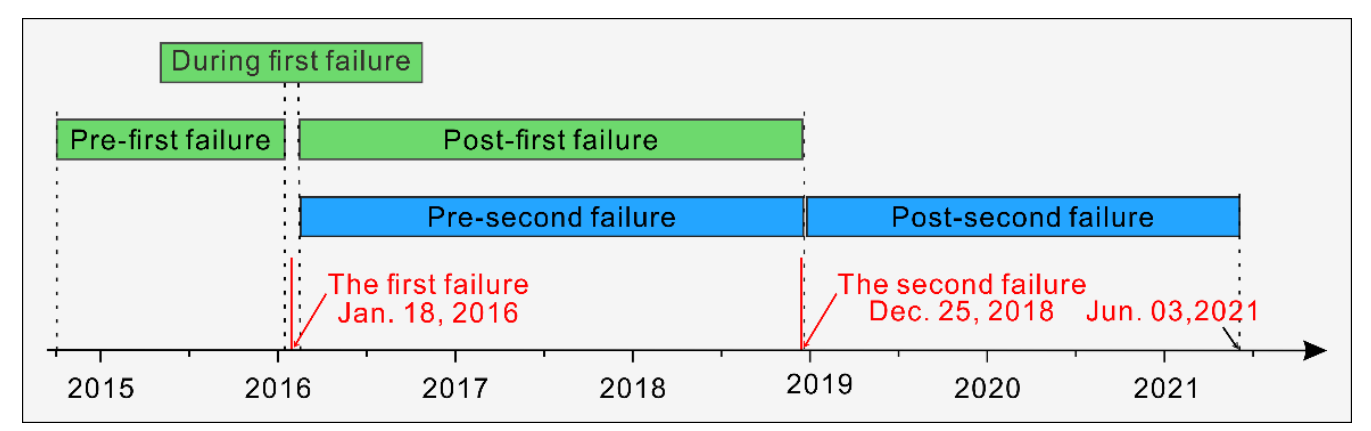

Figure 3. Temporal coverage of the SAR data used in this study.

To retrieve the pre-first failure, pre-second failure, the post-second failure deformation, and the temporal evolution of the Gaojiawan landslide, the small baseline subset (SBAS) interferogram method [46-49] was used to derive the displacement time series from the ascending and descending datasets of the Sentinel-1A satellite. The basic parameters of the SAR images used in this study are presented in Table 1. POD Precise Orbit Ephemerides were used to remove orbit error, and Shuttle Radar Topography Mission (SRTM) digital elevation model (DEM) data covering the study area with a resolution of $30 \mathrm{~m}$ was used as the reference elevation data to eliminate the topographic phase.

Table 1. Basic parameters of the Sentinel-1A satellite datasets.

\begin{tabular}{|c|c|c|c|c|c|c|}
\hline & $\begin{array}{c}\text { Orbit } \\
\text { Direction }\end{array}$ & Path & $\begin{array}{c}\text { Heading } \\
\left({ }^{\circ}\right)\end{array}$ & $\begin{array}{l}\text { Incidence } \\
\text { Angle }\left(^{\circ}\right)\end{array}$ & Data & $\begin{array}{l}\text { Number of } \\
\text { Images }\end{array}$ \\
\hline $\begin{array}{l}\text { Pre-first } \\
\text { failure }\end{array}$ & Ascending & 128 & -13.07 & 34.21 & 14 October 2014-13 January 2016 & 20 \\
\hline During & Ascending & 128 & -13.07 & 34.21 & 13 January 2016-6 February 2016 & 2 \\
\hline disaster & Descending & 135 & -166.89 & 34.05 & 8 December 2015-25 January 2016 & 2 \\
\hline \multirow{2}{*}{$\begin{array}{l}\text { Pre-second } \\
\text { failure }\end{array}$} & Ascending & 128 & -13.07 & 34.21 & 6 February 2016-28 December 2018 & 74 \\
\hline & Descending & 135 & -166.89 & 34.05 & 24 February 2017-28 December 2018 & 50 \\
\hline \multirow{2}{*}{$\begin{array}{l}\text { Post-second } \\
\text { failure }\end{array}$} & Ascending & 128 & -13.07 & 34.21 & \multirow{2}{*}{9 January 2019-3 June 2021} & 69 \\
\hline & Descending & 135 & -166.89 & 34.05 & & 64 \\
\hline
\end{tabular}

Given that the large deformation of the Gaojiawan landslide occurred during the disaster, the Differential SAR interferometry (DInSAR) method [50-53] was used to monitor the deformation based on the two ascending images (acquired on 13 January 2016 and 6 February 2016), and two descending images (acquired on 8 December 2015 and 25 January 2016).

\subsection{Pixel Offset Tracking}

The amplitude-based pixel offset tracking method can measure displacements larger than one meter without the coherence limitations and displacement gradients [33,37]. This method is usually more suitable than InSAR in extracting surface displacements during failure events. However, the accuracy of the range and azimuth deformation extracted using this method is affected by the accuracy of the SAR image registration. SAR image registration error is caused by the serious geometric distortion in the imaging process of the SAR satellite due to the large topographic relief in mountainous regions $[39,54,55]$. To lessen the influence of the geometric distortion, an improved POT method is proposed (Figure 4). Firstly, we orthorectified the master image based on the range-Doppler (RD) location model [56-58]. Second, the geometric model of the radar satellite imaging and the morphological method [59] was used to comprehensively identify the layover, shadowing, and foreshortening regions $[19,54,55,60]$. After masking the geometrical distortions (Figure 5), the master image and slave image were registered and clipped, which registers SAR images more accurately and obtains reliable deformation information. Finally, the 
range and azimuth deformation in the geographic coordinate system was calculated using the POT method $[34,61]$. In this study, the improved POT method was used to monitor the deformation based on the two ascending images (acquired on 13 January 2016 and 6 February 2016) and the two descending images (acquired on 8 December 2015 and 25 January 2016).

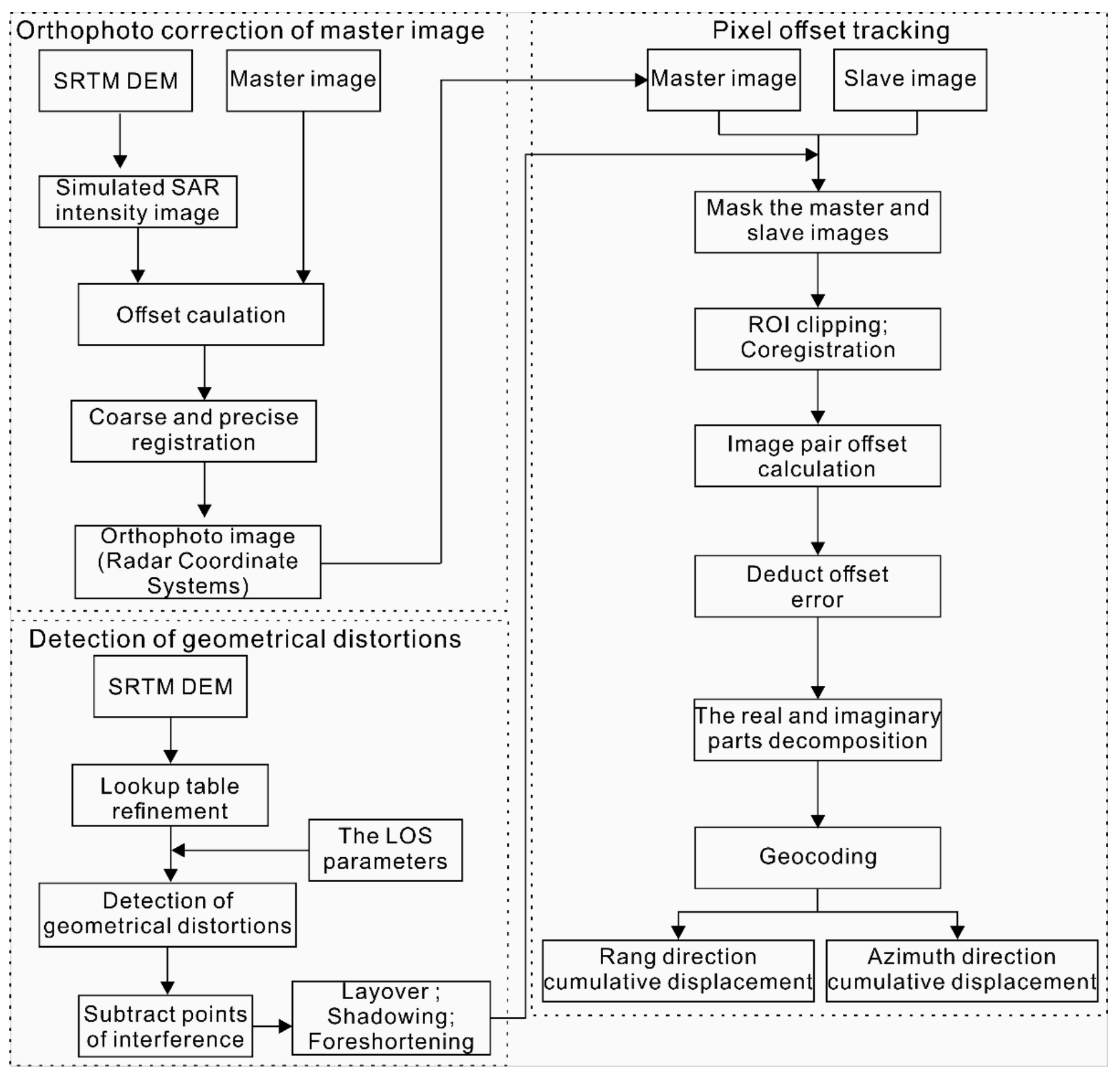

Figure 4. Workflow for processing the Sentinel-1A data using the improved POT method. 

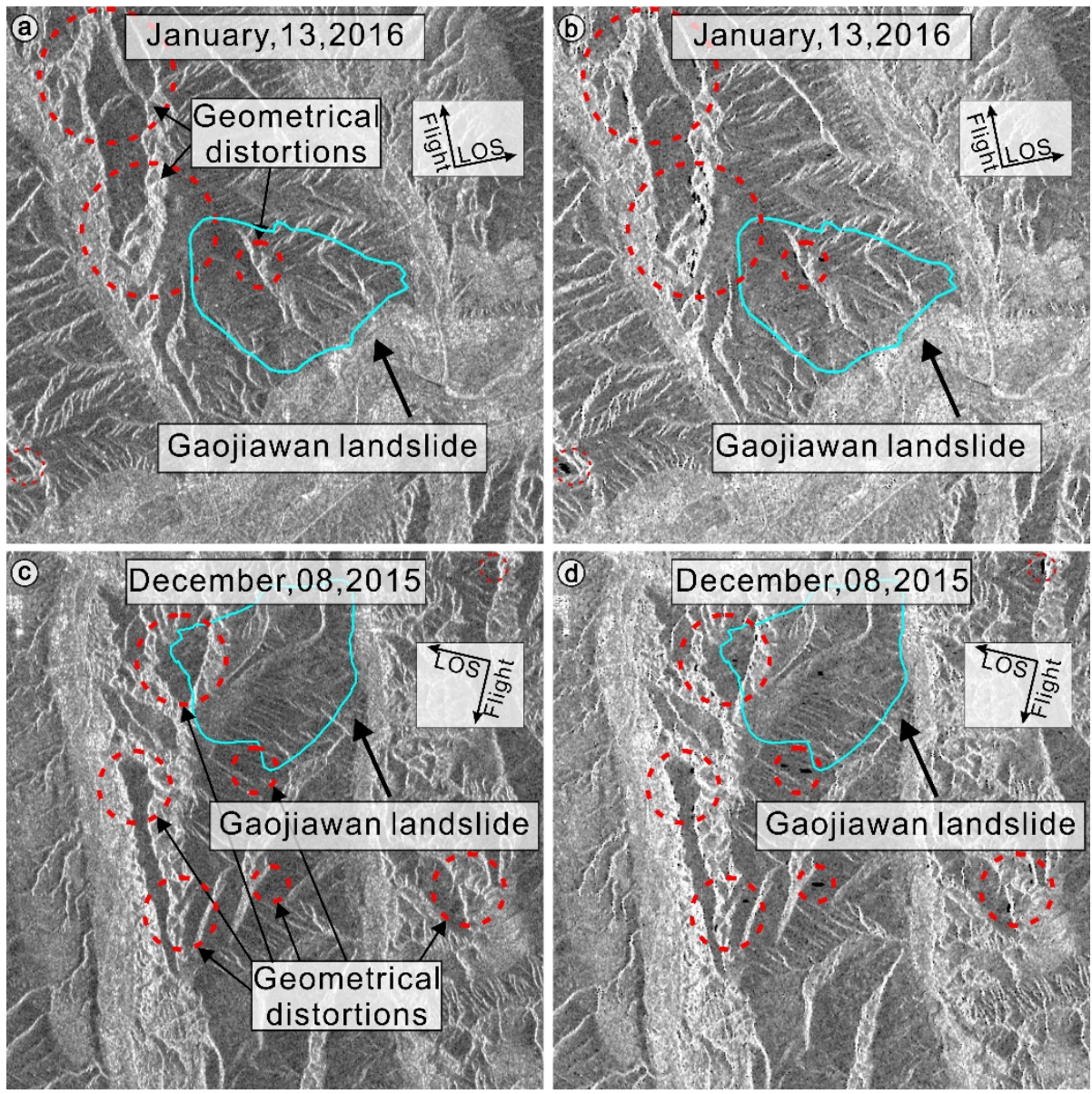

Figure 5. The intensity images and intensity images after geometrical mask distortions in the radar coordinate systems. $(\mathbf{a}, \mathbf{c})$ The intensity images obtained from Sentinel-1A ascending and descending images, respectively; (b,d) The intensity images after geometrical mask distortions obtained from Sentinel-1A ascending and descending images, respectively.

\section{Results and Analysis}

\subsection{Deformation Characteristics of the First Failure}

\subsubsection{Pre-First Failure Surface Deformation of the Landslide}

The SBAS method was used to obtain the pre-failure mean line of sight (LOS) deformation velocity maps of the study area (Figure 6), where negative values represent motion away from the satellite and positive values represent motion toward the satellite. Figure $6 a$ shows that the deformation velocity of the landslide group was $-7-11 \mathrm{~mm} / \mathrm{a}$. The same landslide group (landslide L1, landslide L2, landslide L3, and landslide L7) experienced obvious deformation, but the deformation characteristics were different. Landslide L3 mainly moved away from the satellite along the LOS direction, while the other landslides moved towards the satellite along the LOS direction. It should be noted that landslide L9 had a large sliding area and is located on the mountain nearest to Gaojiawan Village. Its stability is directly related to the safety of the residents and surrounding industrial facilities in Gaojiawan Village. Meng et al. [44] found a series of squeezing and arching phenomena in the buildings around the village on the front of landslide L9 during their field investigations. 

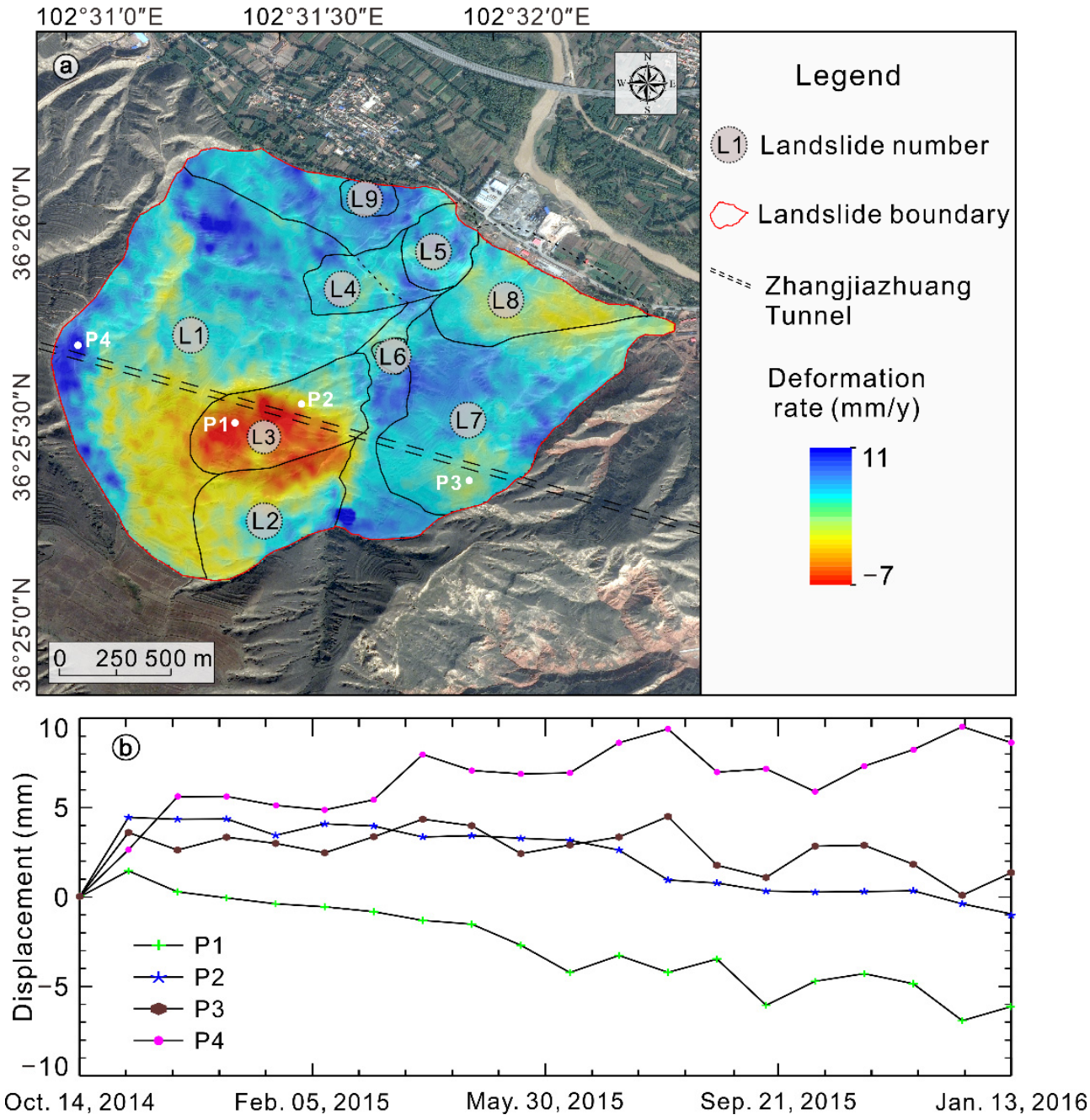

Figure 6. Maps of the mean LOS deformation velocity and the time series LOS displacement, obtained from the ascending SAR datasets from 14 October 2014 to 13 January 2016. (a) Map of the mean LOS deformation velocity. The boundary of the landslide was modified by Meng et al. [44]. The background of (a) is the optical image acquired on 31 December 2015; (b) Plot of the time series LOS displacement.

The Zhangjiazhuang tunnel passes through the underside of the Gaojiawan Mountain. It was found that the surface of landslide L3 underwent significant deformation, with the maximum LOS deformation velocity reaching $-7 \mathrm{~mm} / \mathrm{a}$ (Figure 6a). To further explore the relationship between the landslide and the Zhangjiazhuang tunnel, the four points on both sides of the Zhangjiazhuang tunnel, as shown in Figure 6b, were selected for time series analysis. It was found that the deformation process at points P1 and P4 changed significantly, with maximum cumulative LOS displacements of up to $9 \mathrm{~mm}$. Moreover, the deformation trend primarily exhibits a linear change. Except for slight fluctuations, no significant acceleration was observed before the 18 January 2016 event, though its continuous creep may threaten railway transportation safety.

\subsubsection{Surface Deformation during the First Failure}

To monitor deformation during the disaster, DInSAR analysis was conducted based on the two ascending images (acquired on 13 January 2016 and 6 February 2016) and two descending images (acquired on 8 December 2015 and 25 January 2016). Figure 7 shows two filtered differential interferograms in the same area, obtained from ascending and descending images, respectively. To maintain visual quality, the filtered differential interferogram was not geocoded and was kept in the radar coordinate system. In winter, 
the noise of the interferogram is low, and the fringes caused by displacement can be determined in the interferogram. For example, compared with the stable area, the color changes of the deformation areas from point $A$ to point $B$ (Figure 7a) and from point $C$ to point $\mathrm{D}$ (Figure $\mathrm{7b}$ ) are more drastic. The greater the cycle of color change, the greater the deformation. In particular, in Figure $7 \mathrm{~b}$ it is shown that the entire cycle number of the deformation interference fringe from point $C$ to point $D$ is 4 . However, due to the limitations of the DInSAR method, the maximum displacement between adjacent pixels in a wrapped interferogram cannot exceed $\lambda / 2$, where $\lambda$ is the wavelength $[19,33,38,62]$. Therefore, the regions with rapid movement have displacement gradients that exceed the measurable limits of the DInSAR method.
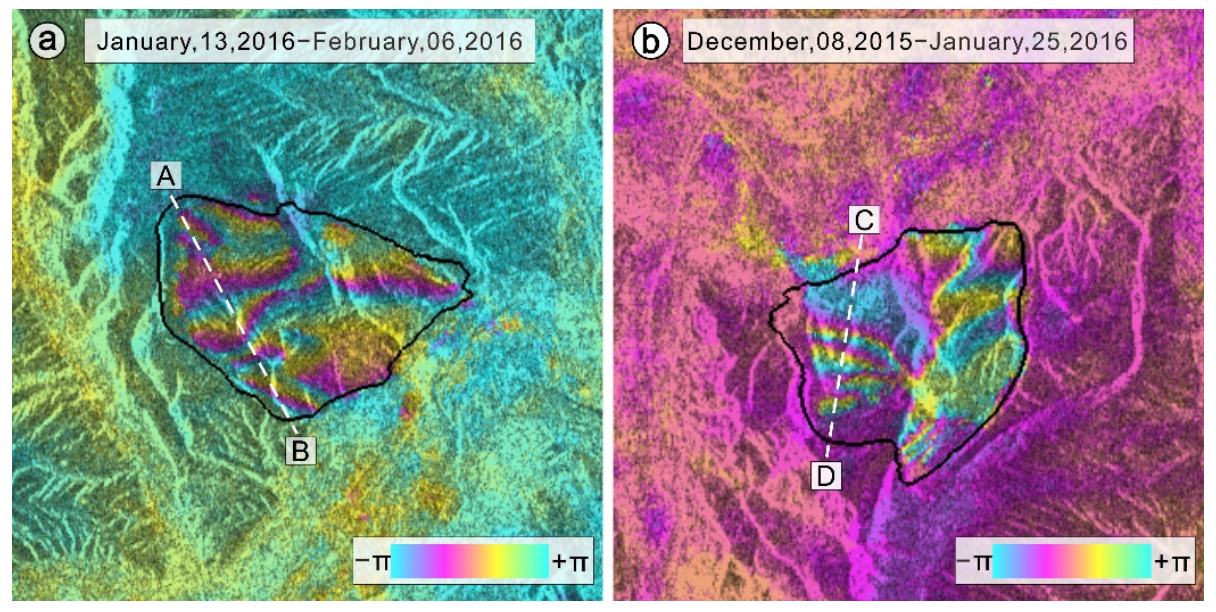

Figure 7. Filtered differential interferograms in the radar coordinate systems. (a,b) Differential interferograms produced from Sentinel-1A ascending and descending images, respectively.

As the magnitude of displacements exceeded the upper limit measurable by the DInSAR method, the amplitude-based improved POT method was employed to retrieve the surface displacements during the disaster. Figure 8 shows the range and azimuth displacements between the two ascending images (acquired on 13 January 2016 and 6 February 2016) and the two descending images (acquired on 8 December 2015 and 25 January 2016) estimated by the improved POT method. As shown in Figure 8a,b, the deformation changes of the entire landslide group were mainly concentrated at the foot of the slope (Landslides L5, L8, and L9), posing a threat to Gaojiawan Village. The LOS deformation obtained by the DInSAR method is consistent with the range direction deformation of the improved POT method. It can be found that the deformation of the upper part of landslide L1 in the range direction (Figure 8a) and the deformation of the right side of landslide L7 in the range direction (Figure $8 \mathrm{c}$ ) are consistent with the position of the interference fringes in Figure 7a,b, respectively. As shown in Figure 8c,d, the main surface movement was concentrated on landslides L2 and L3, consistent with the simulation results obtained by Zhou et al. [8]. That is, the landslide deformation was obvious in the range and azimuth directions. It is worth noting that the deformation direction is from south to north in landslide L7 (Figure 8d), the same direction as the "deforming direction" of the Zhangjiazhuang tunnel measured by the level network of the railway track [8]. Such rapid and large-scale movement may have a certain influence on the stability of the Zhangjiazhuang tunnel. 


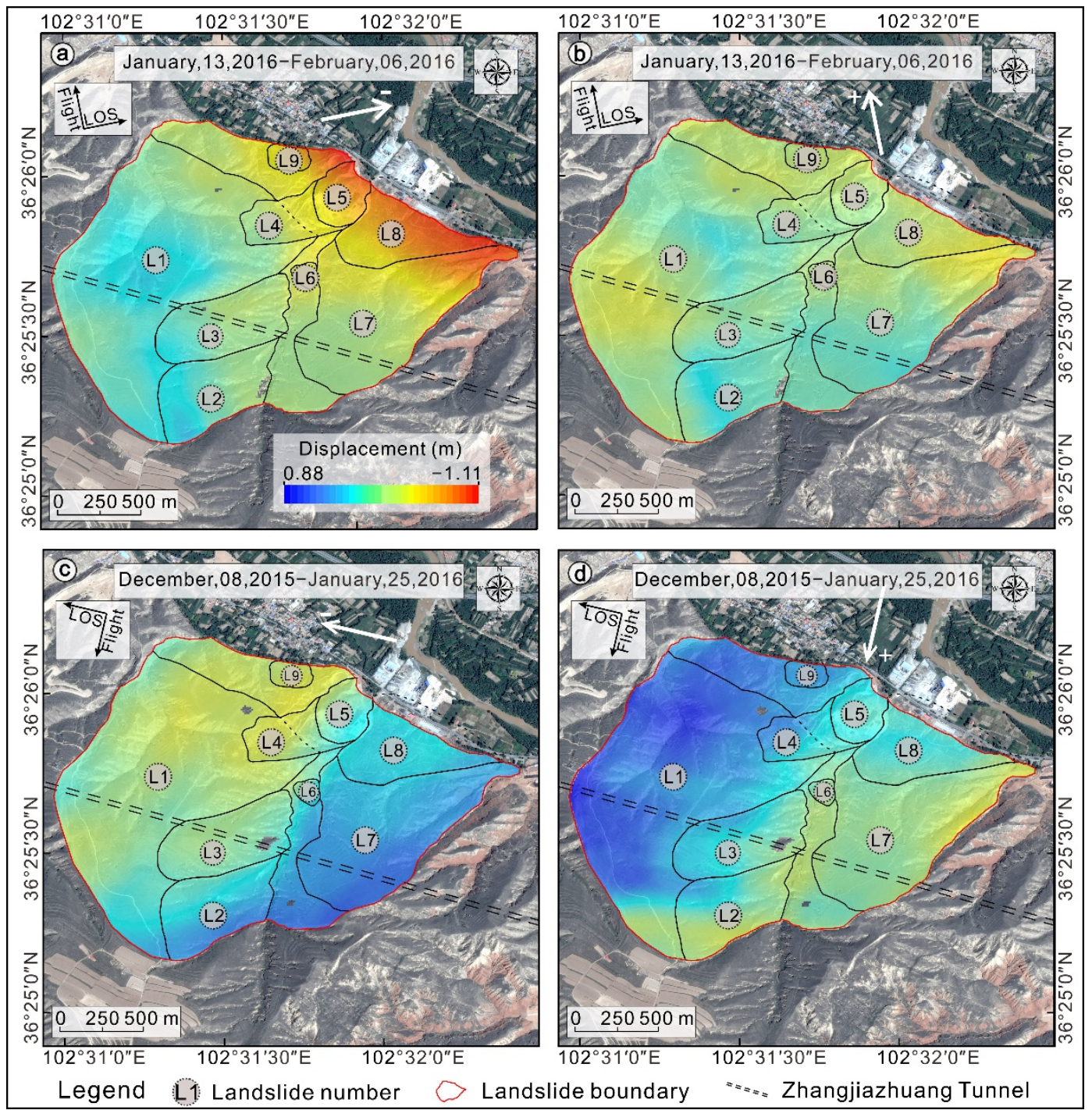

Figure 8. Range and Azimuth displacements obtained by the improved POT method. The back ground is the optical image acquired on 31 December 2015. The boundary of the landslide was modified by Meng et al. [44]. (a,c) Range displacements; (b,d) Azimuth displacements.

\subsection{Deformation Characteristics of the Second Failure}

\subsubsection{Pre-Second Failure Surface Deformation of the Landslide}

Since the geological disaster reoccurred on 25 December 2018 [63], we first studied the pre-failure deformation velocity and spatiotemporal evolution and traced the deformation evolution process of the landslide. Figure 9 shows the mean LOS deformation velocity and the time series LOS displacement plots of the Gaojiawan landslide obtained from the Sentinel-1A ascending and descending datasets. Due to the difference in the observation geometry, the deformation results obtained from the ascending and descending track datasets are different. As shown in Figure 9a, the deformed landslides are mainly distributed in the toes of landslides L1, L2, L3, L4, and L5, and the deformation velocity of the landslide group was $-11-5 \mathrm{~mm} / \mathrm{a}$. However, as can be seen in Figure $9 \mathrm{~b}$, the deformed landslides are mainly distributed in the upper part of landslides L7 and L8, and the deformation velocity of the landslide group was $-9-10 \mathrm{~mm} / \mathrm{a}$. This could show that the ascending data is more sensitive to monitoring landslides facing east, and the descending data is more sensitive to monitoring landslides facing west. To explore the temporal evolution of the Gaojiawan landslide, four points, as shown in Figure 9, were selected for time series analysis. As can be seen from the time series LOS displacement 
plots (Figure 9c), it was found that the deformation process at points P5 and P8 changed significantly, with maximum cumulative LOS displacements of up to $37 \mathrm{~mm}$. It was found that the deformation process at points P6 and P7 changed significantly, with maximum cumulative LOS displacements of up to $15 \mathrm{~mm}$ (Figure 9d). The analyses revealed that the Gaojiawan landslide experienced creep, and the areas of severe deformation exhibit a linear growth trend.
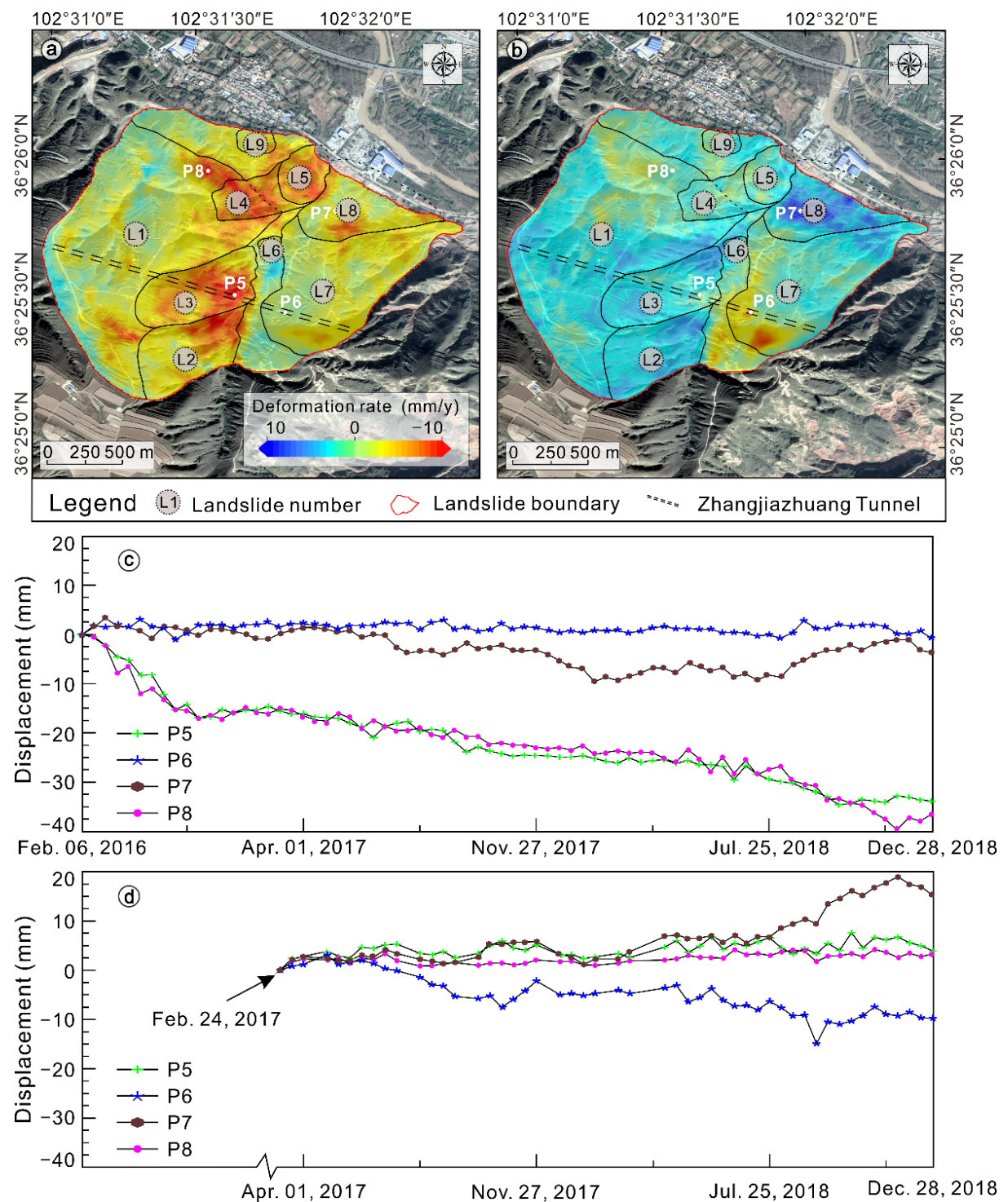

Figure 9. Maps of the mean LOS deformation velocity and the time series LOS displacement obtained from the ascending datasets from 6 February 2016 to 18 December 2018 and the descending SAR datasets from 24 February 2017 to 28 December 2018. The boundary of the landslide was adapted from Meng et al. [44]. The background is the optical image acquired on 31 December 2018. (a,b) Maps of the mean LOS deformation velocity acquired from the ascending and descending orbits, respectively; (c,d) Plots of the time series LOS displacement obtained from the ascending and descending orbits, respectively.

\subsubsection{Post-Second Failure Deformation Monitoring}

To assess the post-failure stability of the slope, the SBAS method was used to derive the deformation velocity and displacement in the study area. The mean LOS deformation velocity and time series LOS displacement plots of the second stage of the Gaojiawan landslide derived from Sentinel-1A images indicate that the Gaojiawan landslide group was in 
deformation (Figure 10). It can be seen from Figure 10a,b that the overall deformation of landslide L3 was obvious. To further illustrate the historic temporal evolution of the slope and search for the deformation signal, the four points, as shown in Figure 10, were selected for time series analysis. An accelerated deformation trend can be observed in the time series LOS displacement plots acquired from the ascending and descending Sentinel-1A datasets (Figure 10c,d). According to the three-stage creeping theory, Saito [64] divided the temporal behavior of creep deformation before landslide failure into three stages, though in the tertiary creep stage the InSAR method may sometimes not monitor the landslide deformation effectively due to the large displacement. However, the acceleration deformation signal of the tertiary creep stage is very important for landslide warning, and it might be taken as a precursory signal for landslide disaster early warning [65,66]. On 31 May 2021, the China Railway Qinghai-Tibet Group Corporation detected an alarm in the Zhangjiazhuang tunnel [41] consistent with our monitoring results. It can be seen that the dense time series derived from the Sentinel-1A observations provide an opportunity to evaluate whether SAR measurements can be used to generate a warning prior to slope failure.
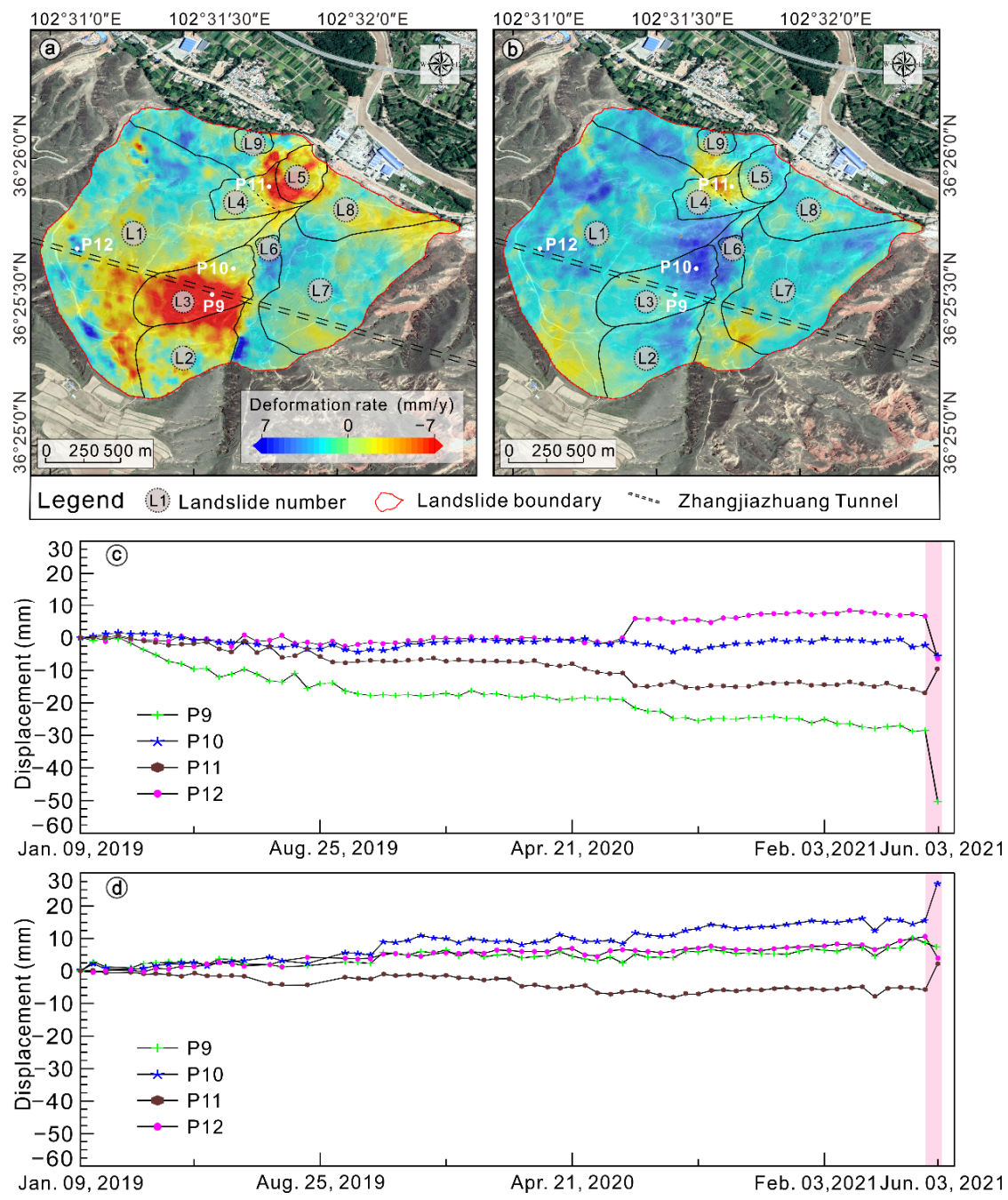

Figure 10. Maps of the mean LOS deformation velocity and the time series LOS displacement obtained from the ascending and descending SAR datasets from 9 January 2019 to 3 June 2021. The boundary of the landslide was adapted from Meng et al. [44]. The background is the optical image acquired on 19 June 2020. (a,b) Maps of the mean LOS deformation velocity acquired from the ascending and descending orbits, respectively; $(\mathbf{c}, \mathbf{d})$ Plots of the time series LOS displacement obtained from the ascending and descending orbits, respectively. 


\section{Discussion}

\subsection{Causative Factors of the Gaojiawan Landslide}

As revealed by our analyses, the Gaojiawan landslide underwent deformation during the extended period from 2014 to 2021. Such deformation might be influenced by various factors, including natural processes and human activities. Here, we analyzed major causative factors on the instability of the Gaojiawan landslide.

Regional geological conditions are conducive to the formation and development of landslides. Under the influence of multiple tectonic systems, active faults are well developed in this area, leading to frequent seismic activity [8,41]. According to a record from Ledu Seismic Station $\left(36.5511^{\circ} \mathrm{N}, 102.3969^{\circ} \mathrm{E}\right.$, about $19 \mathrm{~km}$ away from the Zhangjiazhuang tunnel, Figure 1b), a small earthquake is believed to have occurred on 18 January $2016[8,67]$. Since the earthquake occurred on the same date as the first geological disaster, and according to our research (Figure 6), the Gaojiawan landslide had undergone considerable deformation during the disaster, so it is considered that the earthquake may be the triggering factor of the first geological disaster.

Sustained and concentrated rainfall or groundwater can easily infiltrate loess layers through vertical joints and fissures, which played a key role in inducing the failure of the landslide $[4,68,69]$. During our field investigations, we found that a project at the foot of the Gaojiawan landslide was discharging excess water from the construction site through water pipes (Figure 1h). Through conversations with local villagers, it was found that the drainage volume was large each time, which indicates that the area is rich in groundwater. In addition, a large number of afforestation activities and long-term irrigation activities have been carried out on the Gaojiawan landslide. However, when irrigation water penetrates the soil, usually only a small part can be absorbed by plants, while the remainder will penetrate deep into the groundwater layer. Thus, after a single heavy rainfall or intensive irrigation, groundwater level changes significantly, which may trigger landslides in local areas.

In addition, human activities also have a certain impact on the stability of the slope [44]. To meet the demands of production and transportation, a large number of roads were built on the surface of the Gaojiawan landslide (Figure 1e), which not only partially changed the original landform but also produced partial free faces and reduced the overall stability of the landslide. Numerous buildings were built throughout the slope toe excavation, which resulted in a decrease in the sliding resistance of the lower part of the slope, which is not conducive to the stability of the landslide.

\subsection{Relationship between the Landslide and the Tunnel}

Landslides can cause deformation, damage, or even destruction of underground structures [70-74]. The Zhangjiazhuang tunnel passes through the Gaojiawan landslide, and thus determining the relationship between the Gaojiawan landslide and the tunnel is of great importance. Firstly, the Gaojiawan landslide and the Zhangjiawan tunnel are simultaneously affected by fault activity. In a geological disaster on 18 January 2016, because of the earthquake, the landslide formed the main scarp (Figure 1d), continuously distributed for hundreds of meters. Meanwhile, the Zhangjiazhuang tunnel was also closed. By analyzing deformation information of the landslide in disaster, the deformation direction of landslide L7 (Figure 8d) ran in the same direction as the "deforming direction" of the Zhangjiazhuang tunnel, measured by the level network of the railway track [8]. The fault may have affected the stability of the landslide, which in turn affected tunnel operation. Secondly, the severe deformation area of the Gaojiawan landslide coincided with the position of the tunnel. By comparing the multi-stage deformation velocity maps of the Gaojiawan landslide obtained by ascending and descending datasets (Figures 7-10), it can be seen that the deformation of the Gaojiawan landslide through which the Zhangjiazhuang tunnel passes was relatively severe. Finally, the accelerated deformation of the Gaojiawan landslide also affected the tunnel operation. When the acceleration trend of the Gaojiawan landslide deformation was identified in the time series analysis, an alarm from the Zhangjiazhuang tunnel was also 
monitored by the China Railway Qingzang Group. In summary, influenced by a variety of factors, the Gaojiawan landslide influenced the safety of the Zhangjiazhuang tunnel. Moreover, geological disasters occur frequently along the "Belt and Road", "Sichuan-Tibet Railway", and other major national strategic projects [73-75]. The combined analysis of the phase and amplitude of satellite SAR images conducted in this study provides powerful support for the identification and prevention of landslide disasters.

\subsection{Application and Limitation}

Compared with the conventional POT method, the improved POT method can effectively eliminate the pixel misalignments in SAR images caused by topographic relief and incidence angle difference using an ortho-rectification method [56-58]. In addition, the master image and slave image were registered by masking the geometric distortion region (Figure 5), which improved the accuracy of SAR image registration to a certain extent. The successful practice and application of the improved POT method have laid a good foundation for the study of geological disasters in mountainous regions. The resolution of SAR images used in this study is insufficient to observe all the details of the landslide, but the deformation extracted by SAR remote sensing still provides valuable information for analyzing landslide deformation information in the disaster. With the development of a new generation of high time resolution and high spatial resolution radar satellites, the quality of SAR data will be improved, making POT technology more widely used in landslide research.

Compared with the traditional single time series InSAR method, the combined POT and SBAS method can complement each other to retrieve the entire deformation process of different deformation stages of landslides to better understand the long-term temporal and spatial evolution of the landslide. However, these two methods are also limited by conventional SAR parameters, such as SAR observation mode, sensor parameters, and landslide movement direction. In addition, the POT and SBAS methods have some inherent limitations. On the one hand, the accuracy of the POT method is positively correlated with the resolution of SAR images [34-36]. On the other hand, the SBAS method does not take full advantage of permanent scatterers. Therefore, for a single landslide, high-resolution SAR data and time analysis of joint permanent scatterers and distributed scatterers will have a positive impact on landslide inversion.

\section{Conclusions}

The Gaojiawan landslide is in a state of accelerated deformation, posing a severe threat to the tunnel and the communities at the foot of the mountain. In this study, understanding of the Gaojiawan landslide evolution increased by studying the combination of InSAR and improved POT information. We found that there were obvious signs of surface deformation before the occurrence of the Gaojiawan landslide. Moreover, when the first landslide occurred, regions with rapid movement existed, and their displacement gradient exceeded the measurable limit of DInSAR. The results of the improved POT method showed that the rapid and large-scale movement of the Gaojiawan landslide might have affected the stability of the Zhangjiazhuang tunnel. Meanwhile, the Gaojiawan landslide has experienced long-term creep, and by studying the post-second failure stability of the landslide we identified the acceleration trend in the time series analysis, which can be used as a precursor signal of landslide disaster warning. This is consistent with the news report that the China Railway Qinghai-Tibet Group monitored the warning event in the Zhangjiazhuang tunnel, indicating that the deformation of the landslide had a certain impact on the tunnel. Moreover, the analysis based on the phase and amplitude of satellite SAR images provided reliable monitoring of the Gaojiawan Landslide, which will help us improve our understanding of landslide behavior and mitigate landslide risks.

Author Contributions: Conceptualization, H.Q.; methodology, Y.Z. and H.Q.; software, Y.Z., Z.L. and L.W.; formal analysis, Y.Z., D.Y., Z.L. and J.W.; investigation, Y.P., S.M., C.D. and H.S.; visualization, Y.Z.; writing — original draft preparation, Y.Z.; writing—review and editing, H.Q.; funding acquisition, 
H.Q.; project administration, H.Q.; supervision, H.Q. All authors have read and agreed to the published version of the manuscript.

Funding: This research was funded by the Second Tibetan Plateau Scientific Expedition and Research Program (STEP) (Grant No. 2019QZKK0902), the Natural Science Basic Research Program of Shaanxi (Grant No. 2021JC-40), National Natural Science Foundation of China (Grant No. 41771539), and the International Science \& Technology Cooperation Program of China (Grant No. 2018YFE0100100).

Institutional Review Board Statement: Not applicable.

Informed Consent Statement: Not applicable.

Data Availability Statement: The Sentinel-1A data used in this study were provided by the European Space Agency (ESA), https://scihub.copernicus.eu/dhus/\#/home (accessed on 12 October 2021); POD Precise Orbit Ephemerides used in this study were provided by the ESA, https:/ / scihub.copernicus.eu/gnss/\#/home (accessed on 12 October 2021); and the SRTM DEM was freely downloaded from the website https:/ / earthexplorer.usgs.gov / (accessed on 12 October 2021).

Acknowledgments: The authors thank the ESA for providing free Sentinel-1A datasets. The authors also thank the Google Earth Platform for providing the optical remote sensing images.

Conflicts of Interest: The authors declare no conflict of interest.

\section{References}

1. Petley, D. Global patterns of loss of life from landslides. Geology 2012, 40, 927-930. [CrossRef]

2. Qiu, H.; Cui, P.; Regmi, A.D.; Hu, S.; Wang, X.; Zhang, Y. The effects of slope length and slope gradient on the size distributions of loess slides: Field observations and simulations. Geomorphology 2018, 300, 69-76. [CrossRef]

3. Froude, M.J.; Petley, D.N. Global fatal landslide occurrence from 2004 to 2016. Nat. Hazards Earth Syst. Sci. 2018, 18, $2161-2181$. [CrossRef]

4. Qiu, H.; Cui, Y.; Pei, Y.; Yang, D.; Hu, S.; Wang, X.; Ma, S. Temporal patterns of nonseismically triggered landslides in Shaanxi Province, China. Catena 2020, 187, 104356. [CrossRef]

5. Ma, P.; Cui, Y.; Wang, W.; Lin, H.; Zhang, Y. Coupling InSAR and numerical modeling for characterizing landslide movements under complex loads in urbanized hillslopes. Landslides 2021, 18, 1611-1623. [CrossRef]

6. Peng, J.; Wang, S.; Wang, Q.; Zhuang, J.; Huang, W.; Zhu, X.; Leng, Y.; Ma, P. Distribution and genetic types of loess landslides in China. J. Asian Earth Sci. 2019, 170, 329-350. [CrossRef]

7. Meng, Q.; Confuorto, P.; Peng, Y.; Raspini, F.; Bianchini, S.; Han, S.; Liu, H.; Casagli, N. Regional Recognition and Classification of Active Loess Landslides Using Two-Dimensional Deformation Derived from Sentinel-1 Interferometric Radar Data. Remote Sens. 2020, 12, 1541. [CrossRef]

8. Zhou, S.; Tian, Z.; Di, H.; Guo, P.; Fu, L. Investigation of a loess-mudstone landslide and the induced structural damage in a high-speed railway tunnel. Bull. Int. Assoc. Eng. Geol. Environ. 2020, 79, 2201-2212. [CrossRef]

9. Fan, X.; Xu, Q.; Scaringi, G. Brief communication: Post-seismic landslides, the tough lesson of a catastrophe. Nat. Hazards Earth Syst. Sci. 2018, 18, 397-403. [CrossRef]

10. Meisina, C.; Zucca, F.; Fossati, D.; Ceriani, M.; Allievi, J. Ground deformation monitoring by using the Permanent Scatterers Technique: The example of the Oltrepo Pavese (Lombardia, Italy). Eng. Geol. 2006, 88, 240-259. [CrossRef]

11. Necsoiu, M.; Hooper, D.M. Use of emerging InSAR and LiDAR remote sensing technologies to anticipate and monitor critical natural hazards. In Building Safer Communities—Risk Governance, Spatial Planning and Responses to Natural Hazards; Fra Paleo, U., Ed.; IOS Press: Amsterdam, The Netherlands, 2009; pp. 246-267.

12. Necsoiu, M.; McGinnis, R.; Hooper, D. New insights on the Salmon Falls Creek Canyon landslide complex based on geomorphological analysis and multitemporal satellite InSAR techniques. Landslides 2014, 11, 1141-1153. [CrossRef]

13. Intrieri, E.; Raspini, F.; Fumagalli, A.; Lu, P.; Del Conte, S.; Farina, P.; Allievi, J.; Ferretti, A.; Casagli, N. The Maoxian landslide as seen from space: Detecting precursors of failure with Sentinel-1 data. Landslides 2018, 15, 123-133. [CrossRef]

14. Squarzoni, G.; Bayer, B.; Franceschini, S.; Simoni, A. Pre- and post-failure dynamics of landslides in the Northern Apennines revealed by space-borne synthetic aperture radar interferometry (InSAR). Geomorphology 2020, 369, 107353. [CrossRef]

15. Li, M.; Zhang, L.; Dong, J.; Tang, M.; Shi, X.; Liao, M.; Xu, Q. Characterization of pre- and post-failure displacements of the Huangnibazi landslide in Li County with multi-source satellite observations. Eng. Geol. 2019, 257, 105140. [CrossRef]

16. Wasowski, J.; Bovenga, F. Investigating landslides and unstable slopes with satellite Multi Temporal Interferometry: Current issues and future perspectives. Eng. Geol. 2014, 174, 103-138. [CrossRef]

17. Zhang, Y.; Meng, X.; Chen, G.; Qiao, L.; Zeng, R.; Chang, J. Detection of geohazards in the Bailong River Basin using synthetic aperture radar interferometry. Landslides 2016, 13, 1273-1284. [CrossRef]

18. Zhang, Y.; Meng, X.; Jordan, C.; Novellino, A.; Dijkstra, T.; Chen, G. Investigating slow-moving landslides in the Zhouqu region of China using InSAR time series. Landslides 2018, 15, 1299-1315. [CrossRef] 
19. Colesanti, C.; Wasowski, J. Investigating landslides with space-borne Synthetic Aperture Radar (SAR) interferometry. Eng. Geol. 2006, 88, 173-199. [CrossRef]

20. Shi, X.; Liao, M.; Li, M.; Zhang, L.; Cunningham, C. Wide-Area Landslide Deformation Mapping with Multi-Path ALOS PALSAR Data Stacks: A Case Study of Three Gorges Area, China. Remote Sens. 2016, 8, 136. [CrossRef]

21. Bouali, E.H.; Oommen, T.; Escobar-Wolf, R. Mapping of slow landslides on the Palos Verdes Peninsula using the California landslide inventory and persistent scatterer interferometry. Landslides 2018, 15, 439-452. [CrossRef]

22. Liu, X.; Zhao, C.; Zhang, Q.; Peng, J.; Zhu, W.; Lu, Z. Multi-Temporal Loess Landslide Inventory Mapping with C-, X- and L-Band SAR Datasets-A Case Study of Heifangtai Loess Landslides, China. Remote Sens. 2018, 10, 1756. [CrossRef]

23. Tomás, R.; Pagán, J.I.; Navarro, J.A.; Cano, M.; Casagli, N. Semi-automatic identification and pre-screening of geologi-calgeotechnical deformational processes using persistent scatterer interferometry datasets. Remote Sens. 2019, 11, 1675. [CrossRef]

24. Luo, S.; Feng, G.; Xiong, Z.; Wang, H.; Zhao, Y.; Li, K.; Wang, Y. An Improved Method for Automatic Identification and Assessment of Potential Geohazards Based on MT-InSAR Measurements. Remote Sens. 2021, 13, 3490. [CrossRef]

25. Schlögel, R.; Doubre, C.; Malet, J.-P.; Masson, F. Landslide deformation monitoring with ALOS/PALSAR imagery: A D-InSAR geomorphological interpretation method. Geomorphology 2015, 231, 314-330. [CrossRef]

26. Liu, Z.; Qiu, H.; Ma, S.; Yang, D.; Pei, Y.; Du, C.; Sun, H.; Hu, S.; Zhu, Y. Surface displacement and topographic change analysis of the Changhe landslide on September 14, 2019, China. Landslides 2021, 18, 1471-1483. [CrossRef]

27. Raspini, F.; Bianchini, S.; Ciampalini, A.; Del Soldato, M.; Solari, L.; Novali, F.; Del Conte, S.; Rucci, A.; Ferretti, A.; Casagli, N. Continuous, semi-automatic monitoring of ground deformation using Sentinel-1 satellites. Sci. Rep. 2018, 8, 1-11. [CrossRef]

28. Solari, L.; Del Soldato, M.; Raspini, F.; Barra, A.; Bianchini, S.; Confuorto, P.; Casagli, N.; Crosetto, M. Review of Satellite Interferometry for Landslide Detection in Italy. Remote Sens. 2020, 12, 1351. [CrossRef]

29. Yang, D.; Qiu, H.; Ma, S.; Liu, Z.; Du, C.; Zhu, Y.; Cao, M. Slow surface subsidence and its impact on shallow loess landslides in a coal mining area. Catena 2021, 209, 105830. [CrossRef]

30. Confuorto, P.; Martire, D.D.; Centolanza, G.; Iglesias, R.; Mallorqui, J.J.; Novellino, A.; Calcaterra, D. Post-failure evolution analysis of a rainfall-triggered landslide by multi-temporal interferometry SAR approaches integrated with geotechnical analysis. Remote Sens. Environ. 2017, 188, 51-72. [CrossRef]

31. Dai, K.; Xu, Q.; Li, Z.; Tomás, R.; Fan, X.; Dong, X.; Li, W.; Zhou, Z.; Gou, J.; Ran, P. Post-disaster assessment of 2017 catastrophic Xinmo landslide (China) by spaceborne SAR interferometry. Landslides 2019, 16, 1189-1199. [CrossRef]

32. Zhu, Y.; Qiu, H.; Yang, D.; Liu, Z.; Ma, S.; Pei, Y.; He, J.; Du, C.; Sun, H. Pre- and post-failure spatiotemporal evolution of loess landslides: A case study of the Jiangou landslide in Ledu, China. Landslides 2021, 18, 3475-3484. [CrossRef]

33. Raspini, F.; Ciampalini, A.; Del Conte, S.; Lombardi, L.; Nocentini, M.; Gigli, G.; Ferretti, A.; Casagli, N. Exploitation of Amplitude and Phase of Satellite SAR Images for Landslide Mapping: The Case of Montescaglioso (South Italy). Remote Sens. 2015, 7, 14576-14596. [CrossRef]

34. Raucoules, D.; de Michele, M.; Malet, J.-P.; Ulrich, P. Time-variable 3D ground displacements from high-resolution synthetic aperture radar (SAR). application to La Valette landslide (South French Alps). Remote Sens. Environ. 2013, 139, 198-204. [CrossRef]

35. Fan, X.; Xu, Q.; Alonso-Rodriguez, A.; Subramanian, S.S.; Li, W.; Zheng, G.; Dong, X.; Huang, R. Successive landsliding and damming of the Jinsha River in eastern Tibet, China: Prime investigation, early warning, and emergency response. Landslides 2019, 16, 1003-1020. [CrossRef]

36. Liu, X.; Zhao, C.; Zhang, Q.; Lu, Z.; Li, Z. Deformation of the Baige Landslide, Tibet, China, Revealed Through the Integration of Cross-Platform ALOS/PALSAR-1 and ALOS/PALSAR-2 SAR Observations. Geophys. Res. Lett. 2020, 47, e2019GL086142. [CrossRef]

37. Strozzi, T.; Luckman, A.; Murray, T.; Wegmuller, U.; Werner, C. Glacier motion estimation using SAR offset-tracking procedures. IEEE Trans. Geosci. Remote Sens. 2002, 40, 2384-2391. [CrossRef]

38. Bhattacharya, A.; Mukherjee, K.; Kuri, M.; Vöge, M.; Sharma, M.; Arora, M.K.; Bhasin, R.K. Potential of SAR intensity tracking technique to estimate displacement rate in a landslide-prone area in Haridwar region, India. Nat. Hazards 2015, 79, $2101-2121$. [CrossRef]

39. Qu, T.; Lu, P.; Liu, C.; Wu, H.; Shao, X.; Wan, H.; Li, N.; Li, R. Hybrid-SAR Technique: Joint Analysis Using Phase-Based and Amplitude-Based Methods for the Xishancun Giant Landslide Monitoring. Remote Sens. 2016, 8, 874. [CrossRef]

40. Xiong, Z.; Feng, G.; Feng, Z.; Miao, L.; Wang, Y.; Yang, D.; Luo, S. Pre- and post-failure spatial-temporal deformation pattern of the Baige landslide retrieved from multiple radar and optical satellite images. Eng. Geol. 2020, 279, 105880. [CrossRef]

41. Chinanews. Available online: http://www.chinanews.com/sh/shipin/cns/2021/06-04/news890857.shtml (accessed on 12 October 2021).

42. Gong, Y. Evaluation of Geological Environment Suitability in Ledu Area, Qinghai Province. Master's Thesis, Chang'an University, Xi'an, China, 2018. (In Chinese)

43. TJJJW. Available online: https://baike.baidu.com/reference/8059985/1d1csJCETG6CLwMBdrOL5Il_woXgxnHI0Eb_jh4 HtAJoNxWWDBw5D8GPInm0mFplkR0V9GClu_z2mNFm (accessed on 12 October 2021).

44. Meng, X.; Qi, T.; Zhao, Y.; Dijkstra, T.; Shi, W.; Luo, Y.; Zhang, M. Deformation of the Zhangjiazhuang high-speed railway tunnel: An analysis of causal mechanisms using geomorphological surveys and D-InSAR monitoring. J. Mt. Sci. 2021, 18, 1920-1936. [CrossRef] 
45. Wang, Z.; Zhao, F.; Xie, W.; Lu, R. Formation condition analysis and stability evaluation of Gaojiawan Landslide in Qinghai Province. Bull. Soil Water Conserv. 2020, 40, 81-87. (In Chinese)

46. Berardino, P.; Fornaro, G.; Lanari, R.; Sansosti, E. A new algorithm for surface deformation monitoring based on small baseline differential SAR interferograms. IEEE Trans. Geosci. Remote Sens. 2002, 40, 2375-2383. [CrossRef]

47. Schmidt, D.A.; Bürgmann, R. Time-dependent land uplift and subsidence in the Santa Clara valley, California, from a large interferometric synthetic aperture radar data set. J. Geophys. Res. Space Phys. 2003, 108, 2416. [CrossRef]

48. Casu, F.; Manzo, M.; Lanari, R. A quantitative assessment of the SBAS algorithm performance for surface deformation retrieval from DInSAR data. Remote Sens. Environ. 2006, 102, 195-210. [CrossRef]

49. Hooper, A. A multi-temporal InSAR method incorporating both persistent scatterer and small baseline approaches. Geophys. Res. Lett. 2008, 35, 96-106. [CrossRef]

50. Gabriel, A.K.; Goldstein, R.M.; Zebker, H.A. Mapping small elevation changes over large areas: Differential radar inter-ferometry. J. Geophys. Res. 1989, 94, 9183-9191. [CrossRef]

51. Massonnet, D.; Rabaute, T. Radar interferometry: Limits and potential. IEEE Trans. Geosci. Remote Sens. 1993, 31, 455-464. [CrossRef]

52. Massonnet, D.; Rossi, M.; Carmona, C.; Adragna, F.; Peltzer, G.; Feigl, K.; Rabaute, T. The displacement field of the Landers earthquake mapped by radar interferometry. Nature 1993, 364, 138-142. [CrossRef]

53. Zebker, H.A.; Rosen, P.A.; Goldstein, R.M.; Gabriel, A.; Werner, C.L. On the derivation of coseismic displacement fields using differential radar interferometry: The Landers earthquake. J. Geophys. Res. Space Phys. 1994, 99, 19617-19634. [CrossRef]

54. Cigna, F.; Bateson, L.B.; Jordan, C.J.; Dashwood, C. Simulating sar geometric distortions and predicting persistent scatterer densities for ers-1/2 and envisat c-band sar and insar applications: Nationwide feasibility assessment to monitor the landmass of great britain with sar imagery. Remote Sens. Environ. 2014, 152, 441-466. [CrossRef]

55. Notti, D.; Herrera, G.; Bianchini, S.; Meisina, C.; López-Davalillo, J.C.G.; Zucca, F. A methodology for improving landslide PSI data analysis. Int. J. Remote Sens. 2014, 35, 2186-2214. [CrossRef]

56. Curlander, J.C.; Kwok, R.; Pang, S.S. A post-processing system for automated rectification and registration of spaceborne SAR imagery. Int. J. Remote Sens. 1987, 8, 621-638. [CrossRef]

57. Kellndorfer, J.M.; Dobson, M.C.; Ulaby, F.T. Geocoding for classification of ERS/JERS-1 SAR composites. In Proceedings of the IGARSS '96, 1996 International Geoscience and Remote Sensing Symposium, Lincoln, NE, USA, 31 May 1996; IEEE: Piscataway, NJ, USA, 2002; Volume 4, pp. 2335-2337.

58. Werner, C.; Strozzi, T.; Wegmuller, U.; Wiesmann, A. SAR geocoding and multi-sensor image registration. In Proceedings of the IEEE International Geoscience and Remote Sensing Symposium, Toronto, ON, Canada, 24-28 June 2002; IEEE: Piscataway, NJ, USA, 2003; Volume 2, pp. 902-904.

59. Zhang, T.; Yang, H.; Li, D.; Li, Y.; Liu, J. Identification of layover and shadows regions in SAR images:taking Badong as an example. Bull. Surv. Mapp. 2019, 11, 85-88. (In Chinese)

60. Notti, D.; López-Davalillo, J.C.G.; Herrera, G.; Mora, O. Assessment of the performance of X-band satellite radar data for landslide mapping and monitoring: Upper Tena Valley case study. Nat. Hazards Earth Syst. Sci. 2010, 10, 1865-1875. [CrossRef]

61. González, P.J.; Fernández, J.; Camacho, A.G. Coseismic Three-Dimensional Displacements Determined Using SAR Data: Theory and an Application Test. Pure Appl. Geophys. PAGEOPH 2009, 166, 1403-1424. [CrossRef]

62. Cigna, F.; Bianchini, S.; Casagli, N. How to assess landslide activity and intensity with Persistent Scatterer Interferometry (PSI): The PSI-based matrix approach. Landslides 2013, 10, 267-283. [CrossRef]

63. Chinanews. Available online: http:/ / www.chinanews.com/cj/2019/01-10/8725121.shtml. (accessed on 12 October 2021).

64. Saito, M. Forecasting time of slope failure by tertiary creep. In Proceedings of the 7th International Conference on Soil Mechanics and Foundation Engineering, Mexico City, Mexico; 1969; pp. 677-683.

65. Carlà, T.; Intrieri, E.; Di Traglia, F.; Nolesini, T.; Gigli, G.; Casagli, N. Guidelines on the use of inverse velocity method as a tool for setting alarm thresholds and forecasting landslides and structure collapses. Landslides 2017, 14, 517-534. [CrossRef]

66. Intrieri, E.; Carlà, T.; Gigli, G. Forecasting the time of failure of landslides at slope-scale: A literature review. Earth-Science Rev. 2019, 193, 333-349. [CrossRef]

67. Su, W.; Fen, L.; Ma, R.; Ma, Z. Comparative of disturbance characteristics from horizontal pendulum and vertical pendulum tiltmeter. Seismol. Geomagn. Obs. Res. 2018, 39, 151-163. (In Chinese)

68. Fan, X.; Xu, Q.; Scaringi, G.; Li, S.; Peng, D. A chemo-mechanical insight into the failure mechanism of frequently occurred landslides in the Loess Plateau, Gansu Province, China. Eng. Geol. 2017, 228, 337-345. [CrossRef]

69. Guo, X.; Cui, P.; Chen, X.; Li, Y.; Zhang, J.; Sun, Y. Spatial uncertainty of rainfall and its impact on hydrological hazard forecasting in a small semiarid mountainous watershed. J. Hydrol. 2021, 595, 126049.

70. Regmi, A.D.; Cui, P.; Dhital, M.R.; Zou, Q. Rock fall hazard and risk assessment along Araniko Highway, Central Nepal Himalaya. Environ. Earth Sci. 2016, 75, 1-20. [CrossRef]

71. Vassallo, R.; Mishra, M.; Santarsiero, G.; Masi, A. Interaction of a Railway Tunnel with a Deep Slow Landslide in Clay Shales. Procedia Earth Planet. Sci. 2016, 16, 15-24. [CrossRef]

72. Hu, F.; Leijen, F.J.; Chang, L.; Wu, J.; Hanssen, R.F. Monitoring Deformation along Railway Systems Combining Multi-Temporal InSAR and LiDAR Data. Remote Sens. 2019, 11, 2298. [CrossRef] 
73. Chang, L.; Hanssen, R. Detection of permafrost sensitivity of the Qinghai-Tibet railway using satellite radar interferometry. Int. J. Remote Sens. 2015, 36, 691-700. [CrossRef]

74. Zhang, J.; Zhu, W.; Cheng, Y.; Li, Z. Landslide Detection in the Linzhi-Ya'an Section along the Sichuan-Tibet Railway Based on InSAR and Hot Spot Analysis Methods. Remote Sens. 2021, 13, 3566. [CrossRef]

75. Iqbal, J.; Cui, P.; Hussain, M.L.; Pourghasemi, H.R.; Pradhan, B. Landslide susceptibility assessment along the dubair-dud ishal section of the karakoram highway, northwestern himalayas, pakistan. Acta Geodyn. Geomater. 2021, 18, 137-155. [CrossRef] 